\title{
Endoscopic ultrasound-guided thrombin injection, a management approach for visceral artery pseudoaneurysms
}

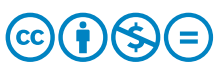

\author{
Authors \\ Institution \\ Department of Gastroenterology, SMS Hospital, Jaipur, \\ India \\ submitted 20.8.2019 \\ accepted after revision 28.10.2019 \\ Bibliography \\ DOI https://doi.org/10.1055/a-1070-9168 | \\ Endoscopy International Open 2020; 08: E407-E412 \\ (c) Georg Thieme Verlag KG Stuttgart · New York \\ eISSN 2196-9736 \\ Corresponding author \\ Shyam Sunder Sharma, DM, Department of \\ Gastroenterology, Room No. 303, Gastro Lab, SMS Medical \\ College and Hospitals, Jaipur 302004, India \\ Fax: +91-141-2564222 \\ shyamsharma4@rediffmail.com
}

Sudhir Maharshi, Shyam Sunder Sharma, Deepak Sharma, Bharat Sapra, Sandeep Nijhawan

\section{ABSTRACT}

Background and study aims Pseudoaneurysms are usually associated with high rates of morbidity and mortality. There are limited data in the literature on endoscopic ultrasound (EUS)-guided thrombin injection for pseudoaneurysms. The aim of this study is to assess the efficacy and safety of EUS-guided thrombin injection for pseudoaneurysms.

Patients and methods This prospective study was conducted in our department between January and December 2018. All patients with symptomatic visceral artery pseudoaneurysms, who were unable to undergo angioembolization, were enrolled consecutively. Data related to demography, laboratory parameters, radiological imaging, pseudoaneurysms, and endotherapy were analyzed.

Results Eight patients with median age 34 years (27-58 years), all men, were studied. The vessel involved was the splenic artery in 5 patients (62.5\%), the left hepatic artery in $2(25 \%)$, and the gastroduodenal artery in 1 patient (12.5\%). The median size of the pseudoaneurysms was $2.9 \mathrm{~cm} \times 2.6 \mathrm{~cm}$ (range, $1.8 \times 1.9-4 \times 5 \mathrm{~cm}$ ). The median thrombin requirement was $400 \mathrm{IU}$ (range, 200-500 IU) for loss of Doppler flow signals. EUS after 3 months showed obliterated pseudoaneurysms in 7 patients $(87.5 \%)$, while recurrence was observed in 1 patient (12.5\%) after 6 weeks.

Conclusions EUS-guided thrombin injection may be a new option for the management of pseudoaneurysms.

\section{Introduction}

Visceral artery pseudoaneurysm is a common complication of pancreatitis seen in $10 \%$ of patients with chronic pancreatitis and with a risk of rupture as high as $50 \%$ and with a rate of mortality after rupture of 15-40\% [1,2]. Therefore, visceral artery pseudoaneurysm should be promptly diagnosed and treated. Digital subtraction angiography with subsequent coil embolization is the standard treatment to occlude the pseudoaneurysm [3].

\section{Indication for endoscopic ultrasound (EUS)-guided thrombin injection}

Occasionally, coil embolization is not possible for various reasons such as short neck of the pseudoaneurysm, inaccessible vascular territory, or angiographically occult pseudoaneurysm, which can be seen on ultrasound and computed tomography (CT) of the abdomen. In these cases, ultrasound or CT-guided percutaneous thrombin injection can be performed $[4,5]$. EUS-guided thrombin injection is another option in these patients, especially when pseudoaneurysm localization is difficult on transabdominal ultrasound, thus we can avoid surgery and morbidity. This procedure is simple, minimally invasive, effective, and cheaper than angioembolization. 


\section{Methods}

Endoscopic ultrasound with a curved linear array transducer in conjunction with a light source was used for this procedure. An intravenous antibiotic was administered 30 minutes before the procedure. The pseudoaneurysm was identified, and the shortest path without any intervening vessel was chosen. Sterile lyophilized human thrombin was used, reconstituted with $1 \mathrm{~mL}$ of calcium chloride and $4 \mathrm{~mL}$ of distilled water to a total of $5 \mathrm{~mL}$. An EchoTip Ultra 22-gauge EUS needle (Cook Medical, Bloomington, Indiana, United States) was used to puncture the pseudoaneurysm, under EUS guidance. After puncture, the reconstituted thrombin was injected in aliquots of $1 \mathrm{~mL}$ until the pseudoaneurysm became echogenic. Further details of the procedure are given later in Materials and methods $[3,6]$.

\section{Outcome}

There is limited data on EUS-guided thrombin injection in visceral artery pseudoaneurysms. Initial case reports revealed successful use of EUS-guided thrombin injection in the management of visceral artery pseudoaneurysms [7-12]. A case series on three patients with visceral artery pseudoaneurysms due to pancreatitis revealed complete thrombosis of the pseudoaneurysm and on short follow-up of 1 month, none of the patients had recurrence of symptoms [3]. Another small case series with short follow-up showed similar results [6]. EUS-guided thrombin injection has also been used successfully along with coil in a bleeding gastroduodenal artery pseudoaneurysm [13]. A recently published case report showed that EUS-guided thrombin can also be used in cystic artery pseudoaneurysm [11]. So the limited available literature favors the use of EUSguided thrombin injection in the management of visceral artery pseudoaneurysms without significant side effects, although long-term follow-up data are not available. Various vascular pathologies and the proximity of the vascular structure to the gastrointestinal tract wall have prompted EUS experts to perform various EUS-guided vascular procedures. High resolution, proximity of vascular pathology to the gastrointestinal tract wall, and real-time guidance offer precise delivery of the intervention. To date, various EUS-guided vascular therapies have been identified such as EUS-guided management of nonvariceal gastrointestinal bleeding, variceal bleeding, pseudoaneurysm, embolization of the portal venous system, and creation of portosystemic shunts [14].

Visceral artery pseudoaneurysms include aneurysms of the celiac, superior, or inferior mesenteric arteries and their branches. Pseudoaneurysms have a high risk of rupture with life threatening consequences [15]. With reported incidences of $0.1-0.2 \%$, visceral artery aneurysms and pseudoaneurysms are relatively rare, but the true incidence is not known since many are asymptomatic [16]. Pseudoaneurysms usually occur after vascular injuries or erosions such as in trauma or inflammation. The increasing use of instrumentation and advanced imaging technologies has led to the increased incidental detection of asymptomatic pseudoaneurysms $[17,18]$. The established procedure to manage pseudoaneurysms is angiography with coil embolization but, due to non-visualization with angio- graphy or inaccessibility (small caliber vessels or short neck of pseudoaneurysm), this technique is not possible in some cases.

Pseudoaneurysms are reported in $10-21 \%$ of patients with chronic pancreatitis, and the splenic artery is most commonly affected [19]. EUS-guided thrombin injection is another possible approach, especially in patients where the established management procedure is not possible. High resolution and realtime guidance by EUS offer an attractive access route and precise delivery of the intervention [14]. Thrombin is the principal enzyme of hemostasis. It catalyzes the conversion of fibrinogen to fibrin and activates procoagulant factors V, VIII, XI, and XIII. It also activates platelets and forms a solid clot. Thrombin activated with calcium chloride causes the immediate formation of a clot which leads to obliteration of the pseudoaneurysm [20]. There are limited data on EUS-guided thrombin injection for treatment of pseudoaneurysms. The aim of this study is to assess the efficacy and safety of EUS-guided thrombin injection in pseudoaneurysms.

\section{Materials and methods}

At SMS Hospital, Jaipur, India between January and December 2018, prospective data were collected from consecutive patients in all age groups with symptomatic visceral artery pseudoaneurysms, and who were unable to undergo coil embolization. The diagnosis of pseudoaneurysm was made on the basis of clinical features, radiological evidence, and endosonographic findings. Each patient underwent detailed clinical evaluation and laboratory investigations including hemogram, prothrombin time, and liver and kidney function tests. A computed tomography (CT) scan along with angiography of the abdomen were performed to look for pseudoaneurysms and any intraabdominal shunts. All patients were admitted and started on standard treatment including intravenous fluid, blood products, and antibiotics. The upper gastrointestinal endoscopy was carried out using a forward viewing endoscope (Olympus GIF-1TQ 160, Tokyo, Japan). After initial stabilization, patients underwent detailed EUS examination and thrombin was injected in the pseudoaneurysm. The required amount of thrombin, procedure time, and any complications were observed. Followup EUS was performed after 72 hours, 1 month, and 3 months to look for recanalization. Follow-up CT scan of the abdomen was also performed after 1 month to identify any side effects distant to the target. The study protocol was approved by the institutional ethics committee. Informed written consent was obtained from each patient before the procedure and the research was carried out in accordance with the Helsinki Declaration.

\section{Technique of endoscopic ultrasound-guided thrombin injection}

Endoscopic ultrasound was performed using a curved linear array transducer (Olympus-GFUCT-180) in conjunction with an EVIS EXERA CLV-180 light source (Olympus Medical System Corp., Tokyo, Japan). An intravenous antibiotic ( $2 \mathrm{~g}$ of ceftriaxone) was administered 30 minutes before the procedure. The procedures were performed under conscious sedation (3 mg in- 

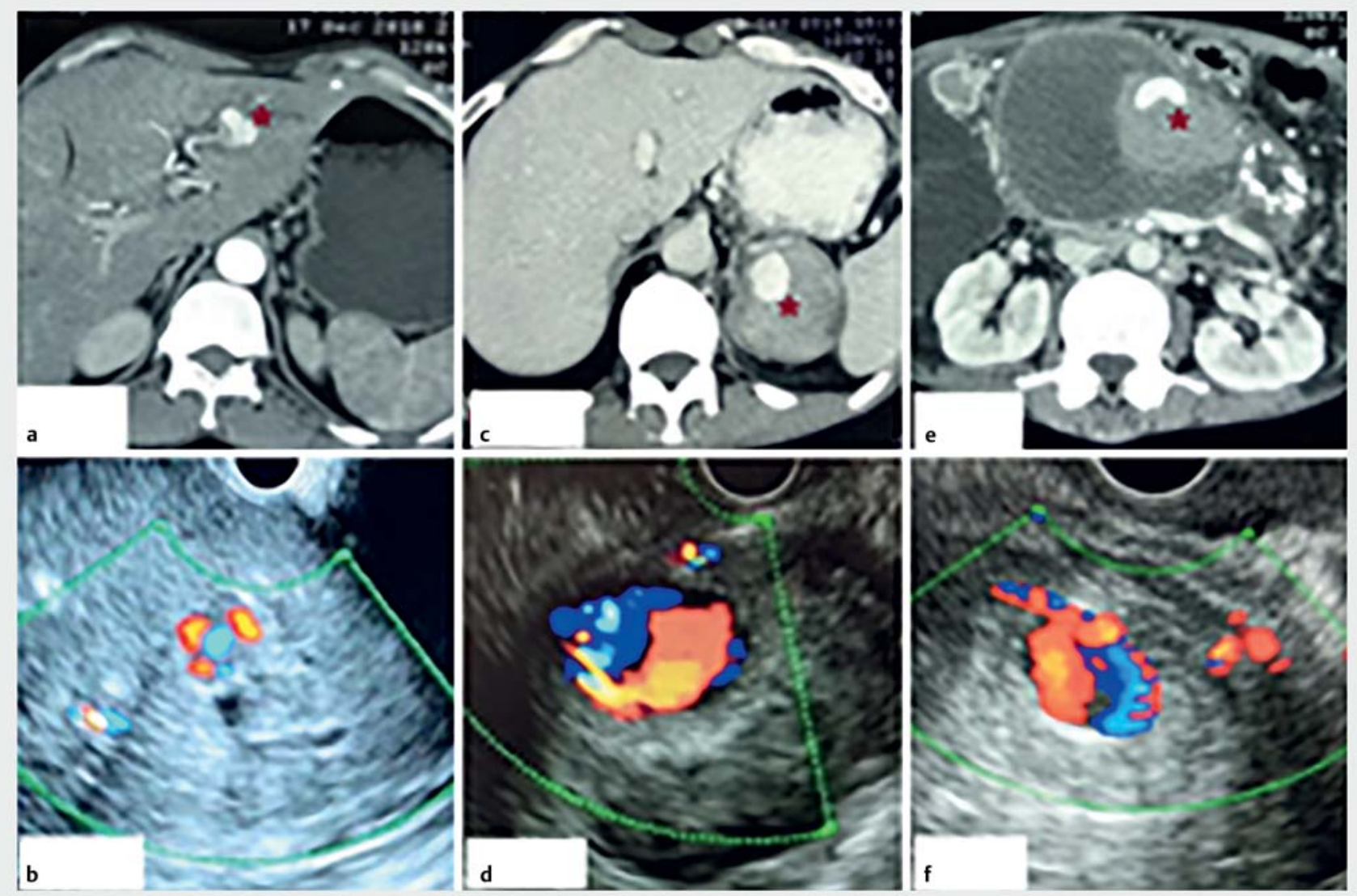

- Fig. 1 a Computed tomography angiography of a patient showing a left hepatic artery pseudoaneurysm $\left({ }^{*}\right)$. b EUS-Doppler of the same patient showing the left hepatic artery pseudoaneurysm. c Computed tomography angiography of a patient showing a splenic artery pseudoaneurysm $\left({ }^{*}\right)$ within pancreatic walled off necrosis. $\mathbf{d}$ EUS-Doppler of the same patient showing the splenic artery pseudoaneurysm. e Computed tomography angiography of a patient showing a splenic artery pseudoaneurysm $\left({ }^{*}\right)$ within pancreatic walled off necrosis. $\mathbf{f}$ EUSDoppler of the same patient showing the splenic artery pseudoaneurysm.

travenous midazolam). The pseudoaneurysm was identified, and the shortest path without any intervening vessel was chosen. Characteristics of the pseudoaneurysm such as vessel involved, size, neck size, and relationship to adjacent structures were assessed. To-and-fro flow of blood in the pseudoaneurysm suggestive of the yin-yang sign was confirmed with color Doppler ( $\mathbf{F i g . 1 b , d , f ) . ~ S t e r i l e ~ l y o p h i l i z e d ~ h u m a n ~ t h r o m b i n ~}$ was used, made from pooled human blood plasma. Just before the procedure, thrombin was reconstituted with $1 \mathrm{~mL}$ of calcium chloride and $4 \mathrm{~mL}$ of distilled water to a total of $5 \mathrm{~mL}$. Thus, each $1 \mathrm{~mL}$ of reconstituted solution contained $100 \mathrm{IU}$ of thrombin. An EchoTip Ultra 22-gauge EUS needle (Cook Medical, Bloomington, Indiana, United States) was used to puncture the pseudoaneurysm, under EUS guidance (> Fig.2a). After puncture, the reconstituted thrombin was injected in aliquots of $1 \mathrm{~mL}$ until the pseudoaneurysm became echogenic. The thrombin was injected into the sac but away from the neck to reduce the risk of distant thromboembolism. The technical success of the procedure was confirmed with loss of Doppler signal inside the pseudoaneurysm sac ( $\mathbf{F i g} \mathbf{2} \mathbf{2 b}$ ) and the needle was removed. A gastroenterologist, who had sufficient experience
(>100 EUS-guided therapeutic procedures), performed these procedures.

\section{Statistical analysis}

Statistical analysis was performed using IBM SPSS Statistics for Windows, trial version 23.0 (IBM Corp, Armonk, NY, United States). Data were expressed as absolute numbers with percentages for categorical variables. Continuous data were expressed as median with interquartile range as appropriate. Data related to demography, laboratory parameters, radiological imaging, pseudoaneurysm, and endotherapy were analyzed.

\section{Results}

In total, eight patients underwent EUS-guided thrombin injection for pseudoaneurysms during the study period. Baseline demographic, clinical, and laboratory parameters are shown in - Table 1. Six patients (75\%) had chronic pancreatitis. The etiology of chronic pancreatitis was alcohol abuse in all six patients. None of the patients had a history of trauma, surgery or any vascular intervention in the past. Two patients (25\%) with left hepatic artery pseudoaneurysms had evidence of hemobilia 

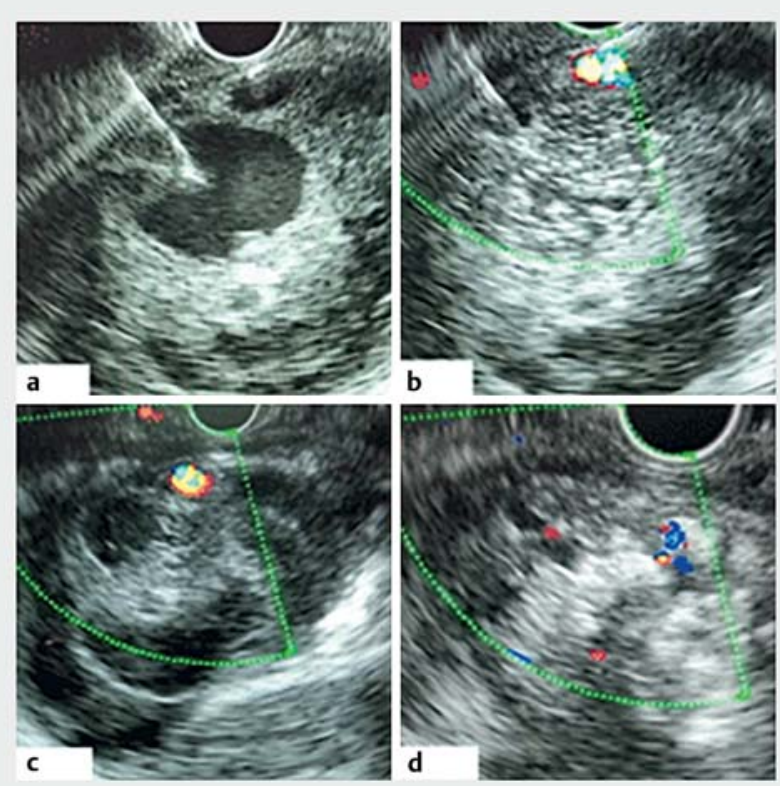

- Fig. 2 a EUS-guided insertion of a 22 gauge needle into pseudoaneurysm. b Loss of Doppler flow signals in pseudoaneurysm after injection of thrombin. c Thrombosed pseudoaneurysm with loss of Doppler flow signals on EUS 72 hours after the procedure. d Thrombosed pseudoaneurysm with loss of Doppler flow signals on EUS 4 weeks after the procedure.

on side view endoscopy. CT of the abdomen revealed that 5 patients $(62.5 \%)$ had pseudoaneurysm of the splenic artery, 2 ( $25 \%$ ) had pseudoaneurysm of the left hepatic artery, and 1 patient $(12.5 \%)$ had gastroduodenal artery pseudoaneurysm ( Fig.1a,c,e). None of the patients had intraabdominal shunts. Procedural and outcome details of individual patients are shown in $>$ Table 2 . One patient with left hepatic artery pseudoaneurysm also had acute cholangitis and required endoscopic retrograde cholangiopancreatography (ERCP) with stenting of the common bile duct (CBD) after thrombin injection and was treated with intravenous antibiotics (Ceftriaxone). In three of our study patients, coil embolization was refused by the cardiologist and radiologist because of non-visualization or inaccessibility of the feeding vessel, and five could not afford to undergo coil angioembolization, as this procedure is very expensive compared to EUS-guided thrombin injection.

\section{Description of lesion}

The median pseudoaneurysm sac size was $2.9 \mathrm{~cm} \times 2.6 \mathrm{~cm}$ $(1.8 \times 1.9-4 \times 5 \mathrm{~cm})$. The median neck length of the pseudoaneurysm from the vessel of origin was $3.1 \mathrm{~mm}(2.8-3.5 \mathrm{~mm})$ and it was narrower than a point source at its origin. Two patients had pancreatic pseudocysts and three had walled off necrosis.

\section{Technical success}

With EUS-guided direct and precise thrombin injection, we were able to achieve $100 \%$ technical success. The median amount of injected thrombin was $400 \mathrm{IU}$ (200-500 IU) which
- Table 1 Demographics and clinical characteristics of the study patients $(n=8)$.

\begin{tabular}{|l|l|}
\hline Parameter & Value \\
\hline Age, median (range), years & $34(27-58)$ \\
\hline Sex, male/female, $\mathrm{n}$ & $8: 0$ \\
\hline Smoker, $\mathrm{n}(\%)$ & $88(100 \%)$ \\
\hline Chronic alcohol consumption, $\mathrm{n}(\%)$ & $6 / 8(75 \%)$ \\
\hline Presenting symptoms, $\mathrm{n}(\%)$ & \\
\hline - Pain abdomen & $8 / 8(100 \%)$ \\
\hline - Melena & $8 / 8(100 \%)$ \\
\hline - Hematemesis & $6 / 8(75 \%)$ \\
\hline - Fever & $2 / 8(25 \%)$ \\
\hline - Jaundice & $2 / 8(25 \%)$ \\
\hline Biochemical parameters & $5.8(4.1-8.8)$ \\
\hline - Hemoglobin, median (range), g/dL & $8.6(6.35-15.12)$ \\
\hline - TLC, median (range), 103/mL & $1.85(1.54-6.95)$ \\
\hline - Platelet count, median (range), $10^{5} / \mathrm{mL}$ & $1.2(0.9-1.52)$ \\
\hline - PT-INR & $3(2-5)$ \\
\hline $\begin{array}{l}\text { Blood transfusion requirement, median } \\
\text { (range), units }\end{array}$ & $3(1-6)$ \\
\hline Follow-up, median (range), months & $400(200-500)$ \\
\hline Thrombin required, median (range), IU & \\
\hline $\begin{array}{l}\text { PT-INR, prothrombin time expressed as international } \\
\text { total lympormalized ratio; TLC, }\end{array}$ \\
\hline
\end{tabular}

depended upon the size of the pseudoaneurysm sac. The median procedure time was 11 minutes (8-15 minutes). After the procedure, patients were monitored closely for hemodynamic stability. Two patients developed post-procedural pain in the abdomen, which required intravenous analgesics. None of the patients had a rupture of the pseudoaneurysm, bleeding or distal arterial thromboembolism. After 72 hours and 4 weeks, repeat EUS showed obliterated pseudoaneurysm in all patients ( Fig. 2c,d).

\section{Clinical success}

Clinical success of the procedure was observed in 7 patients $(87.5 \%)$ after a median sustained follow-up of 6 months (1-9 months), and 1 patient $(12.5 \%)$ had recanalization after 6 weeks, as he presented with hematemesis which required repeat thrombin injection. Follow-up CT scans of the abdomen, performed after 1 month to look for any side effect distant to the target, were normal in all patients. These data indicate that the procedure was very successful in all patients. 
- Table 2 Clinical features, procedural details, and outcomes of the study patients.

\begin{tabular}{|c|c|c|c|c|c|c|c|c|}
\hline $\begin{array}{l}\text { Serial } \\
\text { number }\end{array}$ & $\begin{array}{l}\text { Age, } \\
\text { years }\end{array}$ & Etiology & $\begin{array}{l}\text { Vessel } \\
\text { involved }\end{array}$ & $\begin{array}{l}\text { Pseudoaneur- } \\
\text { ysm size, cm }\end{array}$ & $\begin{array}{l}\text { Pseudoaneur- } \\
\text { ysm neck } \\
\text { length, mm }\end{array}$ & $\begin{array}{l}\text { Thrombin } \\
\text { required, } \\
\text { IU }\end{array}$ & $\begin{array}{l}\text { Procedure } \\
\text { time, min- } \\
\text { utes }\end{array}$ & $\begin{array}{l}\text { Outcome } \\
\text { (after } 6 \\
\text { months) }\end{array}$ \\
\hline 1 & 35 & $\begin{array}{l}\text { Chronic } \\
\text { pancreatitis }\end{array}$ & Splenic artery & $4 \times 5$ & 3.3 & 500 & 12 & Obliterated \\
\hline 2 & 27 & $\begin{array}{l}\text { Chronic } \\
\text { pancreatitis }\end{array}$ & Splenic artery & $4 \times 4$ & 2.8 & 400 & 11 & Obliterated \\
\hline 3 & 43 & $\begin{array}{l}\text { Chronic } \\
\text { pancreatitis }\end{array}$ & Splenic artery & $2.9 \times 2.6$ & 3.1 & 300 & 11 & Obliterated \\
\hline 4 & 55 & $\begin{array}{l}\text { Chronic } \\
\text { pancreatitis }\end{array}$ & Splenic artery & $1.8 \times 1.9$ & 3.1 & 200 & 8 & Obliterated \\
\hline 5 & 30 & Idiopathic & $\begin{array}{l}\text { Left hepatic } \\
\text { artery }\end{array}$ & $2 \times 2$ & 3.1 & 400 & 10 & Obliterated \\
\hline 6 & 31 & Idiopathic & $\begin{array}{l}\text { Left hepatic } \\
\text { artery }\end{array}$ & $2.3 \times 2.2$ & 2.8 & 400 & 15 & Obliterated \\
\hline 7 & 58 & $\begin{array}{l}\text { Chronic } \\
\text { pancreatitis }\end{array}$ & $\begin{array}{l}\text { Gastroduode- } \\
\text { nal artery }\end{array}$ & $4 \times 5$ & 2.9 & 500 & 13 & $\begin{array}{l}\text { Recanalized. } \\
\text { Repeat proce- } \\
\text { dure required } \\
\text { after } 6 \text { weeks }\end{array}$ \\
\hline 8 & 33 & $\begin{array}{l}\text { Chronic } \\
\text { pancreatitis }\end{array}$ & Splenic artery & $2.9 \times 2.6$ & 3.5 & 400 & 10 & Obliterated \\
\hline
\end{tabular}

\section{Discussion}

Our study presents a novel management approach using EUSguided thrombin injection in visceral artery pseudoaneurysms. This treatment was successful in all eight patients in the study. Injection of coil and glue has also been described in the literature for management of visceral artery pseudoaneurysms. A small case series showed the efficacy of EUS-guided transgastric injection of coil and glue in patients with splenic artery pseudoaneurysms. In that study, six patients with splenic artery pseudoaneurysm, who failed angiographic embolization, underwent EUS-guided cyanoacrylate glue and coil injection in pseudoaneurysms. All patients had complete occlusion of the pseudoaneurysms at week 4 and 12 without any complications [21]. Another study proved the efficacy of ultrasound-guided tissue glue injection for the treatment of femoral artery pseudoaneurysms [22]. Initial studies on percutaneous ultrasoundguided thrombin injection concluded that it is a quick, effective, and safe treatment for pseudoaneurysms [18, 19]. A few initial case reports showed the successful use of EUS-guided thrombin injection in the management of visceral artery pseudoaneurysms [7-12]. Another small case series described the successful use of EUS-guided human thrombin with no recurrence on short follow-up [6].

To date, no large study has been published on EUS-guided thrombin injection in pseudoaneurysms. EUS-guided interventions are minimally invasive, can be performed under conscious sedation, and decrease procedure time and hospital stay. They are also simple, effective, and cheaper than angioembolization. Human thrombin does not have the risk of immunological reaction and contamination with prions which was observed in a few cases with bovine thrombin [23]. Thrombin injection can cause complications in the form of downstream embolization into the arterial system and, although rare, this has been well documented [24]. This risk is high if the neck is less than $3 \mathrm{~mm}$ in length or wider than a point source at its origin. In our study, the median neck length was $3.1 \mathrm{~mm}(2.8-3.5 \mathrm{~mm})$ and we injected thrombin into the aneurysmal sac, away from the neck. None of our patients developed distal arterial embolization.

A limitation of this study was that it was a small case series with short duration follow-up.Larger studies with long-term follow-up are needed to further prove the efficacy and safety of the procedure.

In conclusion, EUS-guided thrombin injection provides an alternative for management of visceral artery pseudoaneurysms. It is most useful in patients where endovascular coil embolization is not possible or in patients having a high surgical risk but can be used in all patients as it is simple, minimally invasive, effective and cheaper than angioembolization.

\section{Competing interests}

The authors declare that they have no conflict of interest.

\section{References}

[1] Huiziga WK, Baker LW. Surgical intervention for regional complications of chronic pancreatitis. Int Surg 1993; 78: 315-319 
[2] Gambiez LP, Ernst O], Merlier OA et al. Arterial embolization for bleeding pseudocysts complicating chronic pancreatitis. Arch Surg 1997; 132: 1016-1021

[3] Gamangatti S, Thingujam V, Garg P et al. Endoscopic ultrasound guided thrombin injection of angiographically occult pancreatitis associated visceral artery pseudoaneurysm: case series. World J Gastrointest Endosc 2015; 7: 1107-1113

[4] Elford J, Burrell C, Freeman S et al. Human thrombin injection for the percutaneous treatment of iatrogenic pseudoaneurysms. Cardiovasc Intervent Radiol 2002; 25: 115-118

[5] Vlachou PA, Karkos CD, Bains S et al. Percutaneous ultrasound-guided thrombin injection for the treatment of iatrogenic femoral artery pseudoaneurysms. Eur J Radiol 2011; 77: 172-174

[6] Jhajharia A, Wanjari S, Ashdhir P et al. Endoscopic ultrasound-guided thrombin injection for management of visceral artery pseudoaneurysm: A novel approach. Indian J Gastroenterol 2018; 37: 271-275

[7] Roach H, Roberts SA, Salter $R$ et al. Endoscopic ultrasound-guided thrombin injection for the treatment of pancreatic pseudoaneurysm. Endoscopy 2005; 37: 876-878

[8] Robinson M, Richards D, Carr N. Treatment of splenic artery pseudoaneurysm by endoscopic ultrasound-guided thrombin injection. Cardiovasc Intervent Radiol 2007; 30: 515-517

[9] Lameris R, du Plessis J, Nieuwoudt M et al. A visceral artery pseudoaneurysm: management by EUS guided-thrombin injection. Gastrointest Endosc 2011; 73: 392-395

[10] Chaves DM, Costa FF, Matuguma S et al. Splenic artery pseudoaneurysm treated with thrombin injection guided by endoscopic ultrasound. Endoscopy 2012; 44: E99-E100

[11] Sharma M, Somani P, Talele R et al. EUS-guided thrombin injection of cystic artery pseudoaneurysm leading to Mirrizi's syndrome and hemobilia. Video GIE 2019; 4: 163-165

[12] Rai P, Mohan S, Sharma M. EUS guided thrombin injection in large splenic artery pseudoaneurysm: first report in a patient with tropical chronic pancreatitis. Endoscopy 2014; 46: E355-E356
[13] Sharma M, Somani P, Sunkara T et al. Endoscopic ultrasound-guided coil embolization and thrombin injection of a bleeding gastroduodenal artery pseudoaneurysm. Endoscopy 2019; 51: E36-E37

[14] Bokun T, Grgurevic I, Kujundzic M et al. EUS-guided vascular procedures: a literature review. Gastroenterol Res Pract 2013: doi:10.1155/ 2013/865945

[15] Cordova AC, Sumpio BE. Visceral artery aneurysm and pseudoaneurysm - Should they all be managed by endovascular technique? Ann Vasc Dis 2013; 6: 687-693

[16] Pulli R, Dorigo W, Troisi N et al. Surgical treatment of visceral artery aneurysms: A 25-year experience. J Vasc Surg 2008; 48: 334-342

[17] Ferrero E, Viazzo A, Ferri $M$ et al. Management and urgent repair of ruptured visceral artery aneurysms. Ann Vasc Surg 2011; 25: 981. e7-11

[18] Etezadi V, Gandhi RT, Benenati JF et al. Endovascular treatment of visceral and renal artery aneurysms. J Vasc Interv Radiol 2011; 22: 1246-1253

[19] Ammori B], Alexander DJ, Madan M. Haemorrhagic complications of pancreatitis: presentation, diagnosis and management. Ann R Coll Surg Eng 1998; 8: 316-325

[20] Crawley JT, Zanardelli S, Chion CK et al. The central role of thrombin in hemostasis. J Thromb Haemost 2007; 5: 95-101

[21] Rai P, Kc H, Goel A et al. Endoscopic ultrasound-guided coil and glue for treatment of splenic artery pseudo-aneurysm: new kid on the block. Endosc Int Open 2018; 7: E821-E825

[22] Kurzawski J, Janion-Sadowska A, Sadowski M. A novel minimally invasive method of successful tissue glue injection in patient with iatrogenic pseudoaneurysm. Br J Radiol 2018; 91: 1087

[23] El Ford J, Burrell C, Freeman S et al. Human thrombin injection for the percutaneous treatment of iatrogenic pseudoaneurysms. Cardiovasc Intervent Radiol 2002; 25: 115-118

[24] Sadiq S, Ibrahim W. Thromboembolism complicating thrombin injection of femoral artery pseudoaneurysm: management with intraarterial thrombolysis. J Vasc Interv Radiol 2001; 12: 633-636 